\title{
On the Occurrences of Fractures in Wrench Zones
}

\author{
Shuping Chen ${ }^{1,2 *}$ \\ ${ }^{1}$ State Key Laboratory of Petroleum Resources and Prospecting, China University of Petroleum (Beijing), Beijing, China \\ ${ }^{2}$ College of Geosciences, China University of Petroleum, Beijing, China \\ Email: *csp21c@163.com
}

How to cite this paper: Chen, S.P. (2020) On the Occurrences of Fractures in Wrench Zones. World Journal of Mechanics, 10, 27-38.

https://doi.org/10.4236/wjm.2020.103003

Received: December 26, 2019

Accepted: March 22, 2020

Published: March 25, 2020

Copyright (c) 2020 by author(s) and Scientific Research Publishing Inc. This work is licensed under the Creative Commons Attribution International License (CC BY 4.0).

http://creativecommons.org/licenses/by/4.0/

\begin{abstract}
The formation conditions and time sequences for various types of wrench-related fractures are not clear. Based on a parabola-type failure criterion, this paper has gotten new insights on those questions. In a simple shear, the occurrence of either tensional fractures or Riedel shears is controlled by the ratio $\left(R_{t c}\right)$ of tensile strength to cohesion. In a pure shear, the occurrence of either second order tensional fractures or second order Riedel shears is controlled by the ratio $\left(R_{t c i}\right)$ of tensile strength to cohesion, given a constant inner frictional coefficient. Where the $R_{t c}$ or the $R_{t c i}$ is less than a certain value, the en echelon tensional fractures will occur first. Where the $R_{t c}$ or the $R_{t c i}$ is bigger than the certain value, the Riedel shears will occur first. Where the $R_{t c}$ or the $R_{t c i}$ is equal to the certain value, the en echelon tensional fractures and the Riedel shears will occur simultaneously. The understandings will enhance the research on wrench related fractures and will be of significance in petroleum exploration and development, because fractures are both important accumulation spaces and key migration paths for oil and gas.
\end{abstract}

\section{Keywords}

Wrench, Simple Shear, Pure Shear, Tensional Fracture, Riedel Shear, Time Sequence

\section{Introduction}

Wrench zones and their related structures were common both in outcrops and in oil-bearing areas [1]-[10]. However, there is little analytical discussion on both the conditions and time sequence for the various types of fractures.

The earliest physical modeling of a wrench zone was conducted in a mud model [11]. Based on that model, En echelon tensional fractures (T-fracture) 
and shear fractures were identified later [12]. The synthetic shears (R-shears) and antithetic shears ( $\mathrm{R}$ '-shears) were defined to be Riedel shears [13] [14]. Other secondary structures in a wrench zone include P-shears, Y-shears, and convergent structures like folds and reverse faults [15] [16] [17].

There are debates on the time sequences of various structures all the time. Bartlett et al. [18] considered an identical time for the occurrence of all R-shears, P-shears and R'-shears. Stacey [19], Lajtai [20] and Cho et al. [21] argued that T-tensional fractures will occur first. Physical modeling conducted by Naylor et al. [22] showed that en echelon R-shears would occur in the early stage of a wrench belt development, T-tensional fractures in the middle stage and $\mathrm{R}$ 'shears with cease of the $\mathrm{T}$ fractures in the late stage and further, netted faults and lens would form in this stage as well. While Moore and Byerlee [23] considered the R-shears and P-shears were formed earlier than the $\mathrm{R}$ 'shears. All physical modeling showed that the main displacement zone would be formed at last and where new fractures occur, pre-existing fractures are active [24].

All kinds of structures may occur in an outcrop wrench belt or in a subsurface oil-bearing area [1] [4] [25], including R-shears, R'-shears, P-shears, Y-shears, T-tensional fractures and principal displacement zone. Xu et al. [17] put forward the similarity between the Riedel shear patterns and strike-slip basin patterns. However, the time sequence of the wrench related structures was addressed analytically neither in physical models nor in natural examples.

Based on parabola-type fracture or failure criterion, this paper discusses the stress status and rock mechanics for the occurrence of T-tensional fractures and Riedel shears. Furthermore, the time sequence of their occurrence is addressed as well.

\section{Methodology}

There are two end members of rock deformation patterns, the simple shear and the pure shear (Figure 1). The rock deformation in the upper lithosphere is governed by Coulomb behavior, and the brittle fracture or frictional sliding apply for most the deformation in the upper lithosphere [26] [27]. Typical rock failure criterions include straight line-type, such as Byerlee's law and Mohr-Coulomb failure criterions [28], and parabola-type [29] [30]. For the straight line-type failure criterions do not apply for tensional fractures, a parabola-type failure criterion will be adapted in the following discussions.

\subsection{Simple Shear}

A parabola-type failure criterion is [30]

$$
\begin{gathered}
\tau^{2}=\frac{\tau_{0}^{2}}{\sigma_{I}}\left(\sigma_{I}+\sigma\right) \\
\sigma^{2}+\tau^{2}=\tau_{c}^{2}
\end{gathered}
$$

where $\tau$ is shear stress with positive sign for counter-clock shear and negative sign for clockwise shear. $\sigma$ is normal stress with positive sign for compression 


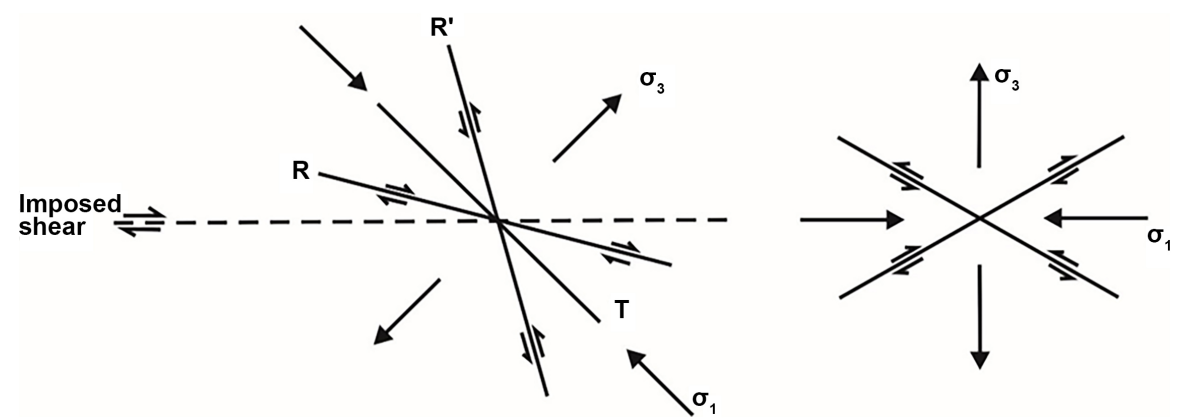

Figure 1. The first order structures in a simple shear (a) and in a pure shear (b). $\mathrm{R}$ is synthetic Riedel shear (R-shear), $\mathrm{R}^{\prime}$ is antithetic Riedel shear ( $\mathrm{R}^{\prime}$-shear), and $T$ is tensile fracture ( $\mathrm{T}$-fracture). The parallel principal shear zone fault (Y-shear), the symmetrical shear (P-shear) to the $\mathrm{R}$ shear and convergent structures were not shown in simple shear (a). (After Harding [15], Twiss and Moores [31] and Cho et al. [21])

and negative sign for extension. $\tau_{0}$ is cohesion. $\sigma_{I}$ is tensile strength under each isotension. $\tau_{c}$ is radius for an extreme circle (c-circle) (Figure 2).

Given $\sigma_{I}=R_{t c} \tau_{0}$ and $\tau_{c}=b \tau_{0}$, the solution of Equation (1) and (2) is

$$
\sigma=\frac{-\tau_{0} \pm \tau_{0} \sqrt{1-4 R_{t c}^{2}\left(1-b^{2}\right)}}{2 R_{t c}}
$$

Suppose

$$
4 R_{t c}^{2}\left(1-b^{2}\right)=1
$$

Equation (3) is now simply

$$
\sigma=\frac{-\tau_{0}}{2 R_{t c}}
$$

where $\sigma=-\sigma_{\mathrm{I}}=-R_{t c} \tau_{0}$, there is one intersection point (Figure 2(a), Figure 2(b)) with

$$
R_{t c}=\frac{\sqrt{2}}{2}
$$

or

$$
\sigma_{I}=\frac{\sqrt{2}}{2} \tau_{0}
$$

In this case of rock mechanics like Equation (7), the tensional fractures and Riedel shears will occur instantaneously. Where the tensile strength is less than $\frac{\sqrt{2}}{2} \tau_{0}$, tensional fractures will be dominant (Figure 2(a), Figure 2(b)). The intersection angles between the tensional fractures and their en echelon axis, the wrench zone are $45^{\circ}$ (Figure $2(\mathrm{c})$ ). Where the tensile strength is bigger than $\frac{\sqrt{2}}{2} \tau_{0}$, the Riedel shears will be dominant instead (Figure 2(d), Figure 2(e)). The angles between the shears and the wrench zone will vary with inner frictional coefficient. 


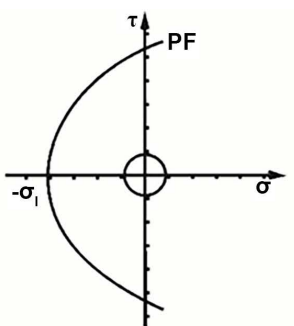

(a)

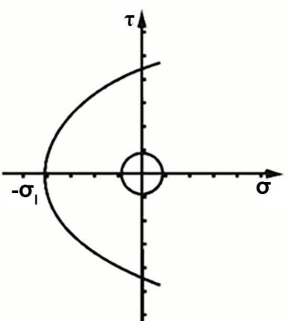

(d)

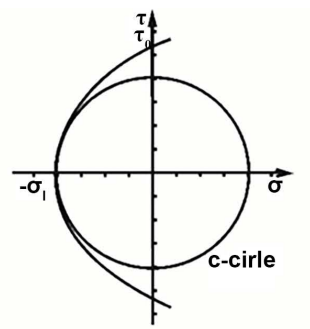

(b)

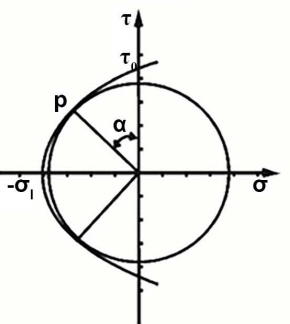

(e)

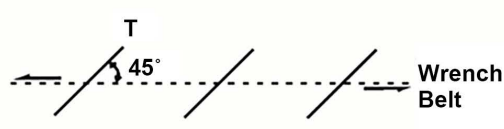

(c)

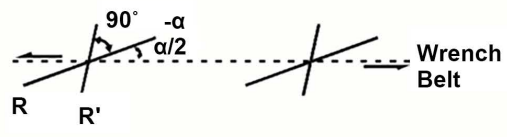

(f)

Figure 2. First order fractures in a simple shear. $P F=$ Parabola-type failure criterion, $\alpha=$ inner frictional angle.

\subsection{Pure Shear}

In a pure shear, the first order fractures are two conjugate shears (Figure 3(a)). The normal stress and shear stress are $\sigma_{f s}$ and $\tau_{f s}$ in a shear fracture (Figure 3(b)). We have

$$
\tau_{f s}=\mu \sigma_{f s}
$$

where $\mu$ is inner frictional coefficient. $\sigma_{f s}$ is the normal stress of the intersection (P) between the $\sigma_{1}-\sigma_{3}$ circle (FC) and the parabola-type failure criterion (PF) (Figure 3(c), Figure 3(d)). The extreme stress Mohr circle for the second order fractures related to the two first order fractures is SC (Figure 3(c)). Its circle center is on the $\sigma$ axis and the circle cross points $\left(\sigma_{f s}, \tau_{f s}\right)$ and $\left(0,-\tau_{f s}\right)$. The second order extreme Mohr circle in formula form can be expressed as

$$
\left(\sigma-\frac{\sigma_{f s}}{2}\right)^{2}+\tau^{2}=\frac{\sigma_{f s}^{2}}{4}\left(1+4 \mu^{2}\right)
$$

Given $\sigma_{I}=R_{t c i} \tau_{0}$ and only one value of $\sigma$, connecting Equation (9) and (1), we have

$$
\left(\sigma_{f s}-\frac{\tau_{0}}{R_{t c i}}\right)^{2}+4 \mu^{2} \sigma_{f s}^{2}-4 \tau_{0}^{2}=0
$$

and

$$
\sigma=\frac{R_{t c i} \sigma_{f s}-\tau_{0}}{2 R_{t c i}}
$$

The $\sigma_{1}-\sigma_{3}$ circle is

$$
\left(\sigma_{f s}-\frac{\sigma_{1}+\sigma_{3}}{2}\right)^{2}+\tau_{f s}^{2}=\left(\frac{\sigma_{1}-\sigma_{3}}{2}\right)^{2}
$$




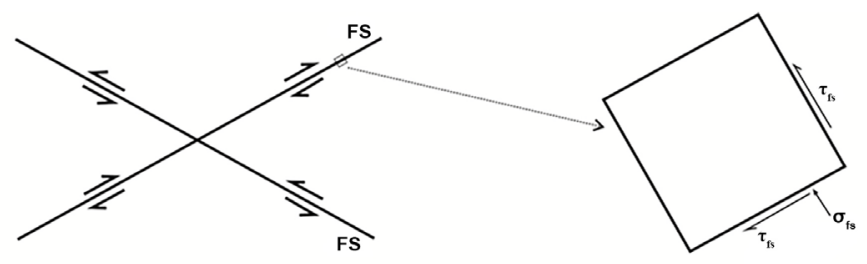

(a)

(b)

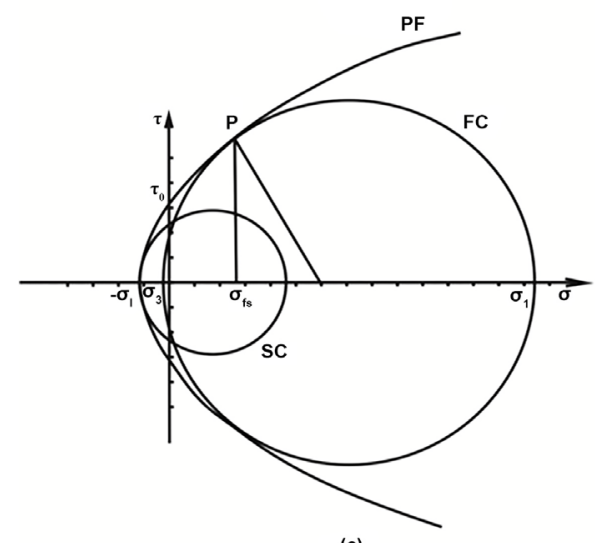

(c)

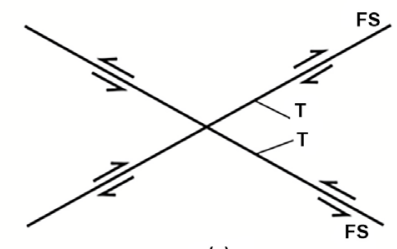

(e)

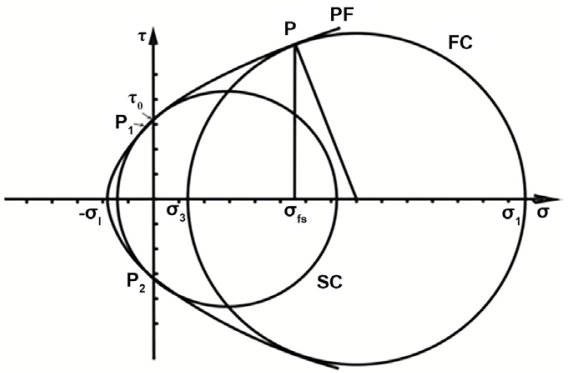

(d)

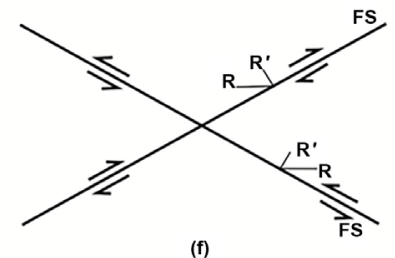

(f)

Figure 3. Extreme stress circles for the first (FC) and second order (SC) fractures in pure shear deformation. $\mathrm{FS}=$ First order shear fracture, $\mathrm{FC}=$ first order extreme stress circle, $\mathrm{SC}=$ second order extreme stress circle, $\mathrm{PF}=$ Parabola-type failure criterion.

The Equation (1) is now

$$
\tau_{f s}^{2}=\frac{\tau_{0}^{2}}{\sigma_{I}}\left(\sigma_{I}+\sigma_{f s}\right)=\frac{\tau_{0}}{R_{t c i}}\left(R_{t c i} \tau_{0}+\sigma_{f s}\right)
$$

Connecting (12) and (13), we have

$$
\left(\frac{\tau_{0}}{R_{t c i}}\right)^{2}-2\left(\sigma_{1}+\sigma_{3}\right) \frac{\tau_{0}}{R_{t c i}}+\left(\sigma_{1}-\sigma_{3}\right)^{2}-4 \tau_{0}^{2}=0
$$

and

$$
\sigma_{f s}=\frac{R_{t c i}\left(\sigma_{1}+\sigma_{3}\right)-\tau_{0}}{2 R_{t c i}}
$$

Connecting (11) and (15), we have

$$
\sigma=\frac{R_{t c i}\left(\sigma_{1}+\sigma_{3}\right)-3 \tau_{0}}{4 R_{t c i}}
$$

where $\sigma=-R_{t c i} \tau_{0}$, a tensional fracture will occur and we have

$$
R_{t c i}=\frac{\sqrt{\left(\sigma_{1}+\sigma_{3}\right)^{2}+48 \tau_{0}^{2}}-\left(\sigma_{1}+\sigma_{3}\right)}{8 \tau_{0}}
$$


or

$$
\sigma_{1}+\sigma_{3}=\frac{\left(3-4 R_{t c i}^{2}\right) \tau_{0}}{R_{t c i}}
$$

Substitute (18) into (14), we have

$$
\sigma_{1}=\frac{\tau_{0}}{2 R_{t c i}}\left(3-4 R_{t c i}^{2}+\sqrt{5-4 R_{t c i}^{2}}\right)
$$

and

$$
\sigma_{3}=\frac{\tau_{0}}{2 R_{t c i}}\left(3-4 R_{t c i}^{2}-\sqrt{5-4 R_{t c i}^{2}}\right)
$$

Substitute (18) into (15), we have

$$
\sigma_{f s}=\frac{\left(1-2 R_{t c i}^{2}\right) \tau_{0}}{R_{t c i}}
$$

Substitute (21) into (10), we have

$$
R_{t c i}=\sqrt{\frac{1}{2} \pm \frac{1}{2} \sqrt{\frac{1}{1+4 \mu^{2}}}}
$$

or

$$
\sigma_{I}=\tau_{0} \sqrt{\frac{1}{2} \pm \frac{1}{2} \sqrt{\frac{1}{1+4 \mu^{2}}}}
$$

In the case of rock mechanics like Equation (23), second order tensional fractures and Riedel shears will occur instantaneously. Whether a positive sign or negative sign in Equation (23) will be determined by the maximum $\left(\sigma_{1}\right)$ and minimum $\left(\boldsymbol{\sigma}_{3}\right)$ principal stresses.

where the tensile strength $\left(\sigma_{\mathrm{I}}\right)$ is less than $\tau_{0} \sqrt{\frac{1}{2} \pm \frac{1}{2} \sqrt{\frac{1}{1+4 \mu^{2}}}}$, tensional fractures will be dominant. Where the tensile strength $\left(\sigma_{\mathrm{I}}\right)$ is bigger than $\tau_{0} \sqrt{\frac{1}{2} \pm \frac{1}{2} \sqrt{\frac{1}{1+4 \mu^{2}}}}$, Riedel shears will be dominant instead.

\section{Discussions}

Study of the relationship between the rock mechanics and the time sequences and types of fractures in a wrench zone can help us explain some natural fractures or physical modeling fractures.

In simple shear, the tensional fractures and R-shears array to be en echelon belts, and penetrative principal displacement zones are absent. Because of that, the rock veins filled in en echelon T-fractures in Figure 4(a), they were formed under left-handed simple shear. In Figure 4(b), an en echelon R-shears occurred, which were formed under right-handed simple shear.

In pure shear, first order conjugate shear fractures should be formed first. Then, second order T-fractures or Riedel shears would be formed and delimited 


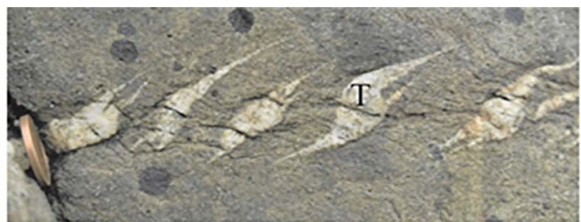

(a)

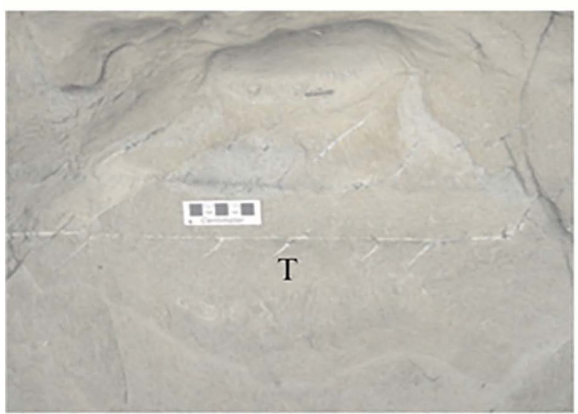

(c)

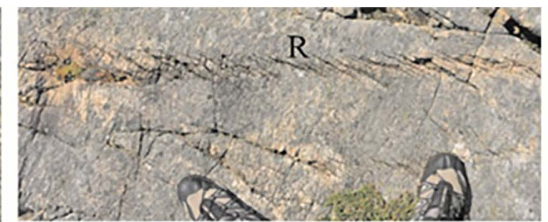

(b)

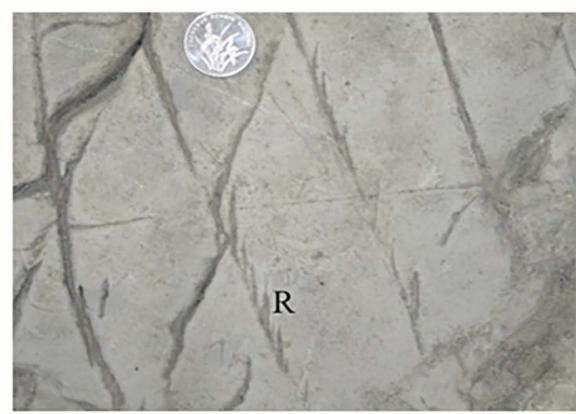

(d)

Figure 4. Natural fractures. (a) En echelon veins, Portugal [32]. (b) R shears [32]. c-en echelon veins delimited by first order shear fractures, Keping uplift, Tarim basin. d-R shears delimited by first order shear fractures, Botanical Garden, Beijing.

by the first order fractures. In Keping uplift, Tarim basin, rock veins filled echelon T-fractures which were delimited by a penetrative left handed principal displacement zone, the first order shear fracture (Figure 4(c)). In the Botanical Garden, Beijing, the en echelon R-shears were delimited by a penetrative right handed principal displacement zone (Figure $4(\mathrm{~d})$ ), which was one of the two first order conjugate shear fractures.

In physical modeling, the mechanic properties of the materials should be considered while the results are discussed. The Riedel shears are common in physical models for the tensile strength is small less than the cohesion [21].

Whether the first order fractures in a simple shear are tensional fractures or Riedel shears depends on tensile strength $\left(\boldsymbol{\sigma}_{I}\right)$ and the cohesion $\left(\boldsymbol{\tau}_{0}\right)$. In a given parabola-type failure criterion, if the tensile strength is less than $\frac{\sqrt{2}}{2} \tau_{0}$ or the ratio $\left(R_{t c}\right)$ of tensile strength to cohesion is less than $\frac{\sqrt{2}}{2}$, the tensional fractures will occur first. If the tensile strength is bigger than $\frac{\sqrt{2}}{2} \tau_{0}$ or the ratio $\left(R_{t c}\right)$ of tensile strength to cohesion is bigger than $\frac{\sqrt{2}}{2}$, the Riedel shears will occur first. If the tensile strength is equal to $\frac{\sqrt{2}}{2} \tau_{0}$, the tensional fractures and the Riedel shears will occur instantaneously. The first order fractures in a pure shear should be two conjugate shears. Subsequently, if tensile strength is less than $\tau_{0} \sqrt{\frac{1}{2} \pm \frac{1}{2} \sqrt{\frac{1}{1+4 \mu^{2}}}}$ or the ratio $\left(R_{t c i}\right)$ of tensile strength to cohesion is less 
than $\sqrt{\frac{1}{2} \pm \frac{1}{2} \sqrt{\frac{1}{1+4 \mu^{2}}}}$, the second order $\mathrm{T}$ fractures will occur first. If the tensile strength is bigger than $\tau_{0} \sqrt{\frac{1}{2} \pm \frac{1}{2} \sqrt{\frac{1}{1+4 \mu^{2}}}}$ or the ratio $\left(R_{t c i}\right)$ of tensile strength to cohesion is bigger than $\sqrt{\frac{1}{2} \pm \frac{1}{2} \sqrt{\frac{1}{1+4 \mu^{2}}}}$, the Riedel shears will occur first. If the tensile strength is equal to $\tau_{0} \sqrt{\frac{1}{2} \pm \frac{1}{2} \sqrt{\frac{1}{1+4 \mu^{2}}}}$, tensional fractures and Riedel shears will occur instantaneously. The positive sign or negative sign will be determined by the maximum $\left(\boldsymbol{\sigma}_{1}\right)$ and minimum $\left(\boldsymbol{\sigma}_{3}\right)$ principal stress. The most important thing is the occurrence of tensional fractures or Riedel shears being determined by the relative magnitude between the tensional strength and the cohesion with the inner frictional coefficient.

The formats and figures (Figure $3(c)$ ) indicate that there are still tensional fractures in high confining pressures in the deep earth with a tensional stress. They are of significance in petroleum exploration and development.

\section{Conclusions}

The occurrence of tensional fractures or Riedel shears in a simple shear depends on tensile strength $\left(\sigma_{I}\right)$ and the cohesion $\left(\tau_{0}\right)$. Where the ratio $\left(R_{t c}\right)$ of tensile strength to cohesion is less than $\frac{\sqrt{2}}{2}$, the tensional fractures will occur first. Where the $R_{t c}$ is bigger than $\frac{\sqrt{2}}{2}$, the Riedel shears will occur first. Where the $R_{t c}$ is equal to $\frac{\sqrt{2}}{2}$, the tensional fractures and the Riedel shears will occur instantaneously.

The occurrence of second order tensional fractures or Riedel shears in a pure shear after the formation of first order conjugate shears depends on tensile strength $\left(\sigma_{I}\right)$, the cohesion $\left(\tau_{0}\right)$ and the inner frictional coefficient $(\mu)$. Where the ratio $\left(R_{t c i}\right)$ of tensile strength to cohesion is less than $\sqrt{\frac{1}{2} \pm \frac{1}{2} \sqrt{\frac{1}{1+4 \mu^{2}}}}$, the second order T-fractures will occur first. Where the $R_{t c i}$ is bigger than $\sqrt{\frac{1}{2} \pm \frac{1}{2} \sqrt{\frac{1}{1+4 \mu^{2}}}}$, the Riedel shears will occur first. Where the $R_{t c i}$ is equal to $\sqrt{\frac{1}{2} \pm \frac{1}{2} \sqrt{\frac{1}{1+4 \mu^{2}}}}$, tensional fractures and Riedel shears will occur instantaneously.

\section{Acknowledgements}

This study was jointly funded by the "national key research and development 
plan-ultra-deep layer, Mesoproterozoic and Neoproterozoic cap sealing property and oil-gas preservation mechanism" (no.2017YFC0603105), the "Mechanism of deep hydrocarbon migration and enrichment in key areas of Sichuan basin" (no.XDA14010306), the "Development in Large-scale oil-gas field and coalbed methane project" - "Reservoir formation conditions and controlling factors in deep-ultra-deep Cambrian in Tarim basin" (no. 2017ZX05005-002-005) and the "Quantitative characterization on various types of strike-slip faults in Jiyang depression" (no. 30200018-19-ZC0613-0118). The author will thank Zongpeng Chen for his revision of English draft.

\section{Conflicts of Interest}

The author declares no conflicts of interest regarding the publication of this paper.

\section{References}

[1] Lowell, J.D. (1985) Structural Styles in Petroleum Exploration. OGCI Publications, Tulsa.

[2] Chen, S.P., Zhou, X.H., Tang, L.J., Wang, Y.B., Lü, D.Y., Sun, M.S. and Qu, D.M. (2010) Wrench-Related Folding: A Case Study of Bohai Sea Basin, China. Marine and Petroleum Geology, 27, 179-190.

https://doi.org/10.1016/j.marpetgeo.2009.08.004

[3] Tavani, S., Quintà, A. and Granado, P. (2011) Cenozoic Right-Lateral Wrench Tectonics in the Western Pyrenees (Spain): The Ubierna Fault System. Tectonophysics, 509, 238-253. https://doi.org/10.1016/j.tecto.2011.06.013

[4] Allen, P.A. and Allen, J.R. (2013) Basin Analysis-Principles and Application to Petroleum Play Assessment. Third Edition, Wiley and Blackwell, Hoboken.

[5] Babaahmadi, A. and Rosenbaum, G. (2014) Late Mesozoic and Cenozoic Wrench Tectonics in Eastern Australia: Insights from the North Pine Fault System (Southeast Queensland). Journal of Geodynamics, 73, 83-99. https://doi.org/10.1016/j.jog.2013.10.001

[6] Alsop, G.I., Weinberger, R., Marco, S. and Levi, T. (2018) Fault and Fracture Patterns around a Strike-Slip Influenced Salt Wall. Journal of Structural Geology, 106, 103-124. https://doi.org/10.1016/j.jsg.2017.10.010

[7] Anderson, H., Walsh, J.J. and Cooper, M.R. (2018) The Development of a Regional-Scale Intraplate Strike-Slip Fault System: Alpine Deformation in the North of Ireland. Journal of Structural Geology, 116, 47-63.

https://doi.org/10.1016/j.jsg.2018.07.002

[8] Belferman, M., Katsman, R. and Agnon, A. (2018) Effect of Large-Scale Surface Water Level Fluctuations on Earthquake Recurrence Interval under Strike-Slip Faulting. Tectonophysics, 744, 390-402. https://doi.org/10.1016/j.tecto.2018.06.004

[9] Chen, S.P., Xu, S.S., Cai, Y. and Ma, X.D. (2018) Wrench Related Faults and Their Control on the Tectonics and Eocene Sedimentation in the L13-L15 Sub-Sag Area, Pearl River Mouth Basin, China. Marine Geophysical Research, 39, 363-381. https://doi.org/10.1007/s11001-017-9328-1

[10] Ghamrya, M.N.E., Amawyb, M.E. and Hagagb, W. (2020) The Role of Late Cretaceous Wrench Tectonics in Hydrocarbon Endowment in El-Gindi Basin, Northern Western Desert, Egypt. Marine and Petroleum Geology, 112, 1-14. 
https://doi.org/10.1016/j.marpetgeo.2019.104093

[11] Cloos, H. (1928) Exiperimente zur inneren Tectonik: Zentralblatt fur Mineralogie. Geologie und Paleontologie b, 12, 609-621.

[12] Riedel, W. (1929) Zur mechanik geologischer brucherscheinungen. Zentralblatt fur Mineralogie, Geologie und Paleontologie B, 354-368.

[13] Hills, E.S. (1963) Elements of Structural Geology. Methuen \& Co. Ltd., London.

[14] Skempton, A.W. (1966) Some Observations on Tectonic Shear Zones. Proceedings of 1 st International Congress on Rock Mechanics, Vol. 1, Lisbon, 329-335.

[15] Harding, T.P. (1974) Petroleum Traps Associated with Wrench Faults. AAPG Bulletin, 58, 1290-1304. https://doi.org/10.1306/83D91669-16C7-11D7-8645000102C1865D

[16] Schreurs, G. (1994) Experiments on Strike-Slip Faulting and Block Rotation. Geology, 22, 567-570. https://doi.org/10.1130/0091-7613(1994)022<0567:EOSSFA >2.3.CO;2

[17] Xu, S.S., Peng, H., Angel, F., et al. (2017) The Similarity between Riedel Shear Patterns and Strike-Slip Basin Patterns. Geological Review, 63, 287-300.

[18] Bartlett, W.L., Friedman, M. and Logan, J.M. (1981) Experimental Folding and Faulting of Rocks under Confining Pressure Part IX. Wrench Faults in Limestone Layers. Tectonophysics, 79, 255-277. https://doi.org/10.1016/0040-1951(81)90116-5

[19] Stacey, T.R. (1981) A Simple Extension Strain Criterion for Fracture of Brittle Rock. International Journal of Rock Mechanics and Mining Sciences, 18, 469-474. https://doi.org/10.1016/0148-9062(81)90511-8

[20] Lajtai, E.Z. (1998) Microscopic Fracture Process in a Granite. Rock Mechanics and Rock Engineering, 31, 237-250. https://doi.org/10.1007/s006030050023

[21] Cho, N., Martin, C.D. and Sego, D.C. (2008) Development of a Shear Zone in Brittle Rock Subjected to Direct Shear. International Journal of Rock Mechanics and Mining Sciences, 45, 1335-1346. https://doi.org/10.1016/j.ijrmms.2008.01.019

[22] Naylor, M.A., Mandl, G. and Sijpesteijn, C.H.K. (1986) Fault Geometries in Basement-Induced Wrench Faulting under Different Initial Stress States. Journal of Structural Geology, 8, 737-752. https://doi.org/10.1016/0191-8141(86)90022-2

[23] Moore, D.E. and Byerlee, J. (1992) Relationships between Sliding Behavior and Internal Geometry of Laboratory Fault Zones and Some Creeping and Locked Strike-Slip Faults of California. Tectonophysics, 211, 305-316. https://doi.org/10.1016/0040-1951(92)90067-G

[24] McKinnon, S.D. and Garrido de la Barra, I. (1998) Fracture Initiation, Growth and Effect on Stress Field: A Numerical Investigation. Journal of Structural Geology, 20, 1673-1689. https://doi.org/10.1016/S0191-8141(98)00080-7

[25] Stone, D.S. (1969) Wrench Faulting and Rocky Mountain Tectonics. Mountain Geologist, 6, 67-79.

[26] Davis, D., Suppe, J. and Dahlen, F.A. (1983) Mechanics of Fold-and-Thrust Belts and Accretionary Wedges. Journal of Geophysical Research, 88, 1153-1172. https://doi.org/10.1029/JB088iB02p01153

[27] Xiao, H. and Suppe, J. (1991) Mechanics of Extensional Wedges. Journal of Geophysical Research, 96, 10301-10318. https://doi.org/10.1029/91JB00222

[28] Kohlstedt, D.L., Evans, B. and Mackwell, S.J. (1995) Strength of the Lithosphere: Constraints Imposed by Laboratory Experiments. Journal of Geophysical Research, 100, 17587-17602. https://doi.org/10.1029/95JB01460 
[29] Griffith, A.A. (1920) The Phenomena of Rupture and Flow in Solids. Philosophical Transactions. Royal Society, London, Series A, 221, 163-198. https://doi.org/10.1098/rsta.1921.0006

[30] Chen, Q.X., Wang, W.X., Sun, Y., et al. (1998) The Investigation of Rock Mechanics and Tectonic Stress Field. Geological Publishing House, Beijing.

[31] Twiss, R.J. and Moores, E.M. (2007) Structural Geology. W. H. Freeman and Company, New York.

[32] Fossen, H. (2016) Structural Geology. Second Edition, Cambridge University Press, Cambridge. 


\section{Appendix: List of Variables and Abbreviations}

FC: first order extreme stress circle

FS: first order shear fracture

$\mathrm{P}$ : intersection between the first order extreme stress circle (FC) and the parabo-

la-type failure criterion $(\mathrm{PF})$

PF: Parabola-type failure criterion

$R_{t c}:$ ratio of tensile strength to cohesion in simple shear

$R_{t c i}:$ ratio of tensile strength to cohesion in pure shear

$R$ : synthetic Riedel shear (R-shear)

$\mathrm{R}$ ! antithetic Riedel shear ( $\mathrm{R}$ '-shear)

$\mathrm{SC}$ : second order extreme stress circle

$T$ : tensile fracture (T-fracture)

$\alpha$ : inner frictional angle

$\sigma$. normal force

$\sigma_{1}:$ maximum principal stress

$\sigma_{3}:$ minimum principal stress

$\sigma_{\mathrm{fs}}:$ normal stress in a pre-existing shear fracture

$\sigma_{\mathrm{I}}$ : tensile strength

$\tau$. shear stress

$\tau_{0}$ : cohesion

$\tau_{\dot{c}}$ radius for an extreme circle (c-circle)

$\boldsymbol{\tau}_{f s}$ : shear stress in a pre-existing shear fracture 